\title{
Research on AGC ancillary service transaction mode in China at
}

\author{
present stage \\ Yongxiu He ${ }^{\mathrm{a}}$, Qian Chen $^{a^{*}}$, Yan Chang ${ }^{a}$, Xiao Gao ${ }^{b}$, Peipei You ${ }^{b}$ \\ ${ }^{a}$ School of Economics and Management, North China Electric Power University, Beijing \\ 102206, China \\ ${ }^{\mathrm{b}}$ State Grid Energy Research Institute, Beijing 100052, China \\ *Corresponding author: Qian Chen, Master's degree, 18146539756, 1559065389@qq.com
}

\begin{abstract}
The ancillary service plays an important role in the development of electricity market and the optimal allocation of power resources as the guarantee of power supply reliability and power quality. This paper takes automatic generation control (AGC) as an example, to explore its transaction mode. Firstly, analyse the feasible trading mode in centralized market and decentralized market respectively. Then, based on the characteristics of ancillary service market in China, the analytic network process (ANP) method is used to determine the index system and weight, and finally get AGC ancillary services applicable trading model ranking.
\end{abstract}

Key words: AGC ancillary service; ANP; transaction mode; comprehensive evaluation

\section{Introduction}

AGC refers to the generator set in the specified range of output adjustment, tracking power dispatch instructions, and adjusting the power output to meet the power system frequency and contacting line power control requirements of the service.

YAO Peng et al. ${ }^{1}$ deployed the AGC service based on analytic hierarchy process (AHP), according to its performance-price ratio, the performance, capacity price, energy price and position of AGC service; Huang Yonghao et al. ${ }^{2}$ put forward the operation of ancillary services mechanism and the transaction process and other specific details of the operation; Zou Jianping et al. ${ }^{3}$ proposed cost allocation methods and pricing mechanism of reactive power ancillary services in the competitive electricity market environment. 


\section{AGC ancillary service available trading mode}

\subsection{Centralized transaction ancillary service trading mode}

Mode I: Centralized trading, uniform clearing.

Mode I is that the market operators release AGC market demand in advance, and accept the AGC service providers' declaration, and then adjust the ranking price of each AGC service supplier, and form the uniform marginal price of the market on the basis of meeting the demand of AGC. The details are shown in Fig. 1 as below.

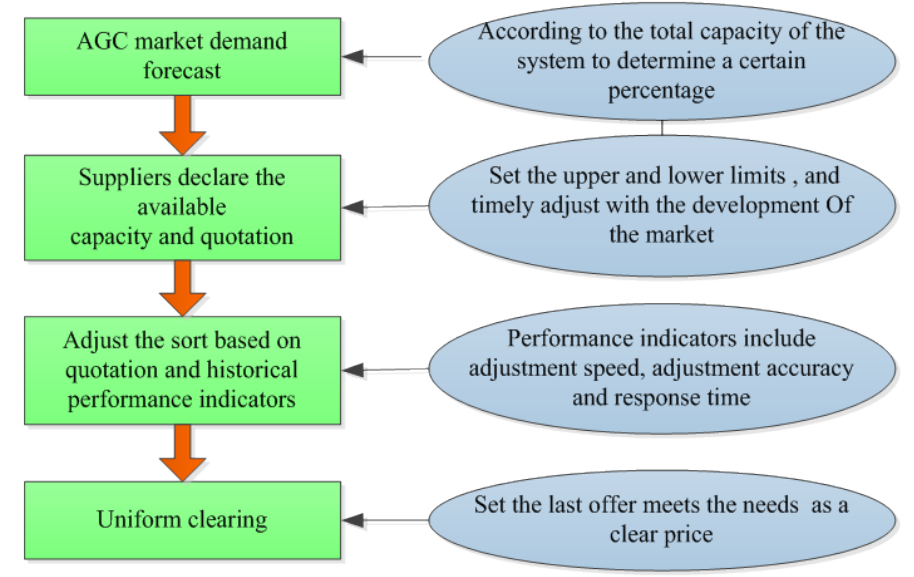

Fig. 1 - Trading pattern of Mode I

Mode II: Listing transactions.

This mode refers to that the dispatching organization or power plants who can provide the AGC service, list at the trading center according to the AGC demand forecast, and delist by the power plants who meet the demand and checked by the dispatching organization, as shown in Fig. 2 as below.
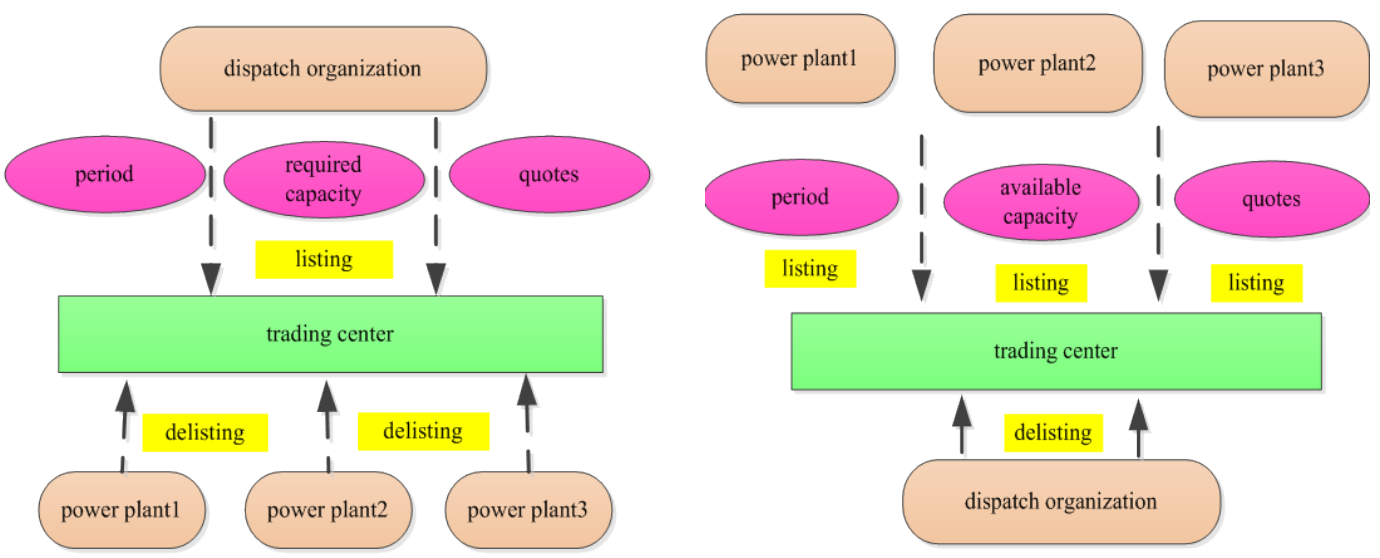

Fig. 2 - Trading pattern of Mode II 


\subsection{Decentralized transaction ancillary service trading mode}

Mode III: Matching trading, uniform clearing

The mode refers to the sellers and the buyers offer bidirectional quoted, the trading center to match, and use the uniform clearing method to settlement, which is shown in Fig. 3 as below.

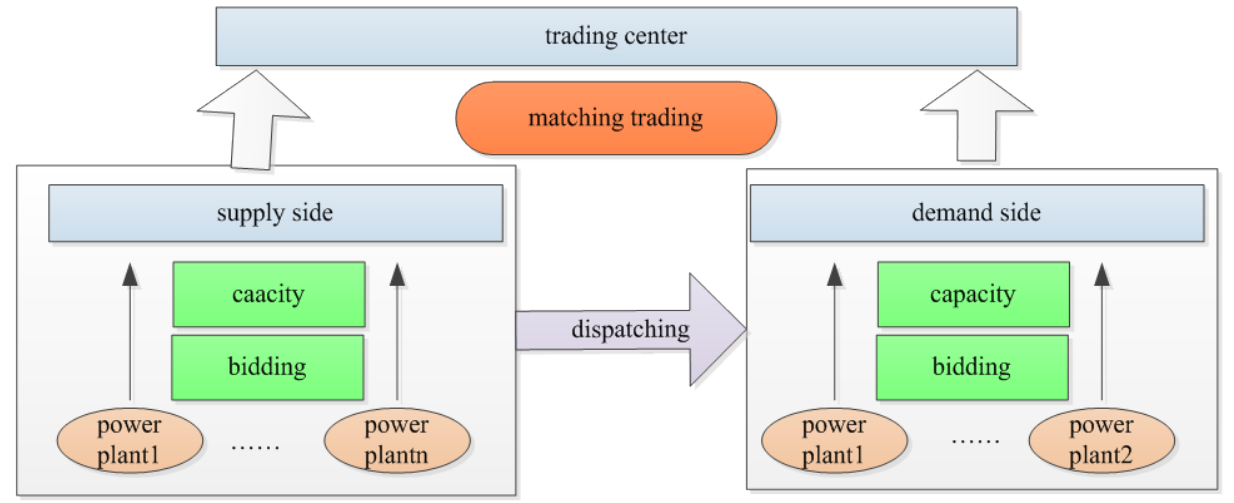

Fig. 3 - Trading pattern of Mode III

Mode IV: Listing transactions in decentralized transaction

The mode refers to that the power plants list in the trading center according to their own AGC demand forecast, and delisted by the power plants who meet the demand, then, the security agencies check the security before the transaction, the price of settlement is the delisting price. Mode V: Bilateral negotiation transactions

The mode refers to that the AGC ancillary service demand side and the supply side negotiate at first, and after agreeing, the dispatching capacity, the adjustment time and the contract price will be reported to the dispatching organization, and the dispatching organization should check the security before completing the transaction according to the contract.

\section{Comprehensive evaluation system of ancillary service market transaction mode}

\subsection{Construction of evaluation index system of ancillary service market transaction mode}

ANP is applicable to complex decision-making systems with internal dependencies and feedback relationships that are developed on the basis of AHP; using the combination of ANP and Delphi method to determine the weight of the indicators ${ }^{4}$, the evaluation index system is shown in table 1 as below. 
Table 1 -Evaluation index system of ancillary service market transaction mode

\begin{tabular}{|c|c|c|}
\hline Target layer(A) & Primary targets & Secondary index \\
\hline \multirow{13}{*}{$\begin{array}{l}\text { evaluation index system } \\
\text { of ancillary service } \\
\text { market transaction mode }\end{array}$} & \multirow{3}{*}{ technical indicators (B1) } & Enforceability(C1) \\
\hline & & convenience(C2) \\
\hline & & promotion level(C3) \\
\hline & \multirow{3}{*}{ market indicators(B2) } & market participation(C4) \\
\hline & & market transaction electricity(C5) \\
\hline & & trading price volatility(C6) \\
\hline & \multirow{4}{*}{ social benefit indicators(B3) } & total social surplus(C7) \\
\hline & & buyer satisfaction(C8) \\
\hline & & seller satisfaction(C9) \\
\hline & & policy support(C10) \\
\hline & \multirow{3}{*}{$\begin{array}{l}\text { power grid efficiency } \\
\text { indicators(B4) }\end{array}$} & transmission efficienc(C11)y \\
\hline & & scheduling cost(C12) \\
\hline & & power supply reliability(C13) \\
\hline
\end{tabular}

\subsection{Evaluation of the weight of evaluation index of ancillary service market}

Using the Super Decisions software to calculate and compare the scores of experts, the relationship between the evaluation indicators at all levels is shown in Fig. 4, the weight coefficient is shown in Table 2.

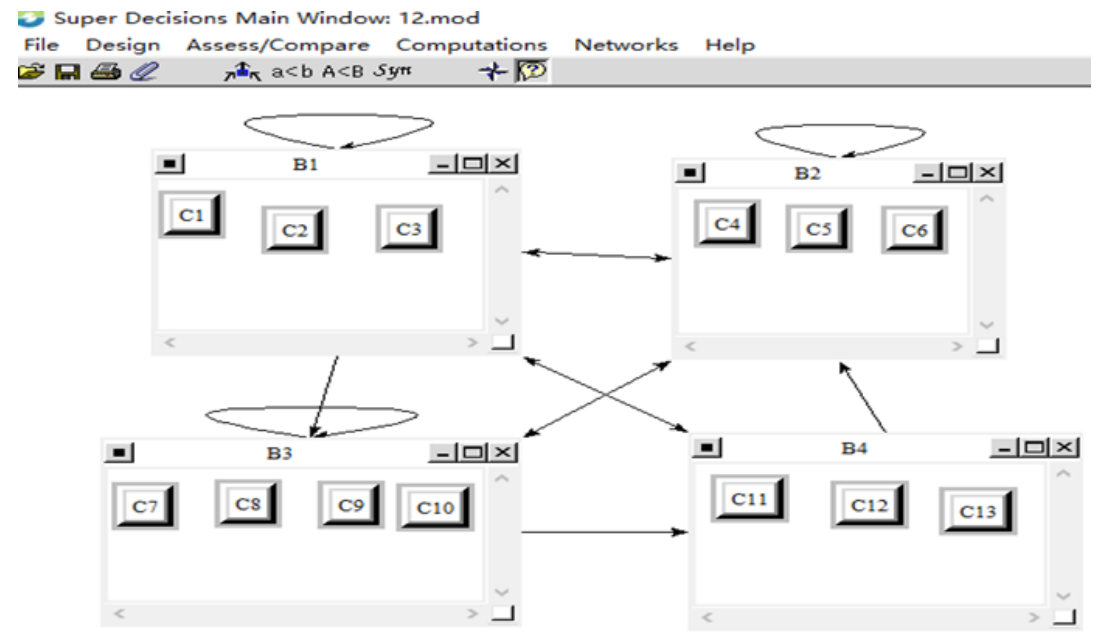

Fig. 4 -The relationship between the evaluation indicators at all levels

China is currently in a variety of trading patterns coexist in the market transition period, with the continuous development of the market and the technology continues to mature and other factors change, the indicators of the property values are shown in the table 3 as below: 
Table 2 -The weight coefficient of evaluation indicators

\begin{tabular}{|c|c|c|c|c|}
\hline Target layer(A) & Primary targets(B) & weight & Secondary index(C) & weight \\
\hline \multirow{13}{*}{$\begin{array}{l}\text { evaluation index } \\
\text { system of } \\
\text { ancillary service } \\
\text { market } \\
\text { transaction mode }\end{array}$} & \multirow{3}{*}{$\begin{array}{c}\text { technical } \\
\text { indicators (B1) }\end{array}$} & \multirow{3}{*}{0.149} & Enforceability(C1) & 0.333 \\
\hline & & & convenience(C2) & 0.109 \\
\hline & & & promotion level(C3) & 0.558 \\
\hline & \multirow{3}{*}{ market indicators(B2) } & \multirow{3}{*}{0.447} & market participation(C4) & 0.556 \\
\hline & & & $\begin{array}{c}\text { market transaction } \\
\text { electricity(C5) }\end{array}$ & 0.239 \\
\hline & & & trading price volatility(C6) & 0.204 \\
\hline & \multirow{4}{*}{$\begin{array}{c}\text { social benefit } \\
\text { indicators(B3) }\end{array}$} & \multirow{4}{*}{0.283} & total social surplus(C7) & 0.298 \\
\hline & & & buyer satisfaction(C8) & 0.086 \\
\hline & & & seller satisfaction(C9) & 0.086 \\
\hline & & & policy support(C10) & 0.528 \\
\hline & \multirow{3}{*}{$\begin{array}{l}\text { power grid efficiency } \\
\text { indicators(B4) }\end{array}$} & \multirow{3}{*}{0.121} & transmission efficienc(C11)y & 0.18 \\
\hline & & & scheduling cost(C12) & 0.069 \\
\hline & & & power supply reliability(C13) & 0.751 \\
\hline
\end{tabular}

Table 3 -The attribute value of each index after processing

\begin{tabular}{|c|c|c|c|c|c|}
\hline Secondary index(C) & Mode I & Mode II & Mode III & Mode IV & Mode V \\
\hline Enforceability(C1) & 9 & 8 & 9 & 7 & 5 \\
\hline convenience(C2) & 7 & 6 & 8 & 7 & 8 \\
\hline promotion level(C3) & 6 & 3 & 8 & 2 & 4 \\
\hline market participation(C4)(\%) & 40 & 10 & 70 & 30 & 50 \\
\hline market transaction electricity(C5)(billion kWh) & 20 & 10 & 60 & 25 & 20 \\
\hline trading price volatility(C6)(\%) & 2 & 3 & 4 & 3 & 1 \\
\hline total social surplus(C7)(billion yuan) & 6 & 2 & 8 & 5 & 3 \\
\hline buyer satisfaction(C8)(\%) & 60 & 70 & 85 & 80 & 100 \\
\hline seller satisfaction(C9)(\%) & 75 & 70 & 90 & 85 & 100 \\
\hline policy support(C10) & 6 & 5 & 8 & 7 & 10 \\
\hline transmission efficiency(C11)(billion yuan) & 2 & 1 & 6 & 3 & 0.5 \\
\hline scheduling cost(C12) & 7 & 6 & 3 & 2 & 1 \\
\hline power supply reliability(C13)(\%) & 99.2 & 99.1 & 99 & 98.5 & 98.8 \\
\hline
\end{tabular}

The original data is processed in a dimensionless and consistent manner, which is as follows:

$$
U_{i}=\frac{X_{i}-X_{\min }}{X_{\max }-X_{\min }} \times 40+60
$$

For indicators the smaller the better, the following formula is used:

$$
U_{i}=\frac{X_{\max }-X_{i}}{X_{\max }-X_{\min }} \times 40+60
$$

where $U_{i}$ indicates the normalized data, $X_{i}$ is the original data value, $X_{\max }$ is the maximum value in the data, $X_{\min }$ is the minimum value in the data. 
On the basis of each index and corresponding weight, calculate the comprehensive evaluation value, the formula is:

$$
S=\sum_{i=1}^{n} W_{i} S_{i}
$$

where $S$ is the comprehensive evaluation value and $w_{i}$ is the weight of the index $i, \mathrm{~s}_{i}$ is the value of the index $i$.

The data after standardized processing is shown in table 4 as below:

Table 4 -The attribute value of each index after processing

\begin{tabular}{|c|c|c|c|c|c|}
\hline Secondary index(C) & Mode I & Mode II & Mode III & Mode IV & Mode V \\
\hline Enforceability(C1) & 100 & 90 & 100 & 80 & 60 \\
\hline convenience(C2) & 80 & 60 & 100 & 80 & 100 \\
\hline promotion level(C3) & 86.67 & 66.67 & 100 & 60 & 73.33 \\
\hline market participation(C4)(\%) & 80 & 60 & 100 & 73.33 & 86.67 \\
\hline $\begin{array}{c}\text { market transaction electricity(C5)(billion } \\
\text { kWh) }\end{array}$ & 68 & 60 & 100 & 72 & 68 \\
\hline trading price volatility(C6)(\%) & 86.67 & 73.33 & 60 & 73.33 & 100 \\
\hline total social surplus(C7)(billion yuan) & 86.67 & 60 & 100 & 80 & 66.67 \\
\hline buyer satisfaction(C8)(\%) & 60 & 70 & 85 & 80 & 100 \\
\hline seller satisfaction(C9)(\%) & 66.67 & 60 & 86.67 & 80 & 100 \\
\hline policy support(C10) & 68 & 60 & 84 & 76 & 100 \\
\hline transmission efficiency(C11)(billion yuan) & 70.91 & 63.64 & 100 & 78.18 & 60 \\
\hline scheduling cost(C12) & 60 & 66.67 & 86.67 & 93.33 & 100 \\
\hline power supply reliability(C13)(\%) & 100 & 94.29 & 88.57 & 60 & 77.14 \\
\hline
\end{tabular}

\section{Results and discussions}

According to the above formulas and the weight of each index and the value of each index, we can calculate the above five kinds of AGC auxiliary service transaction model comprehensive evaluation value in table 5 as follows:

Table 5 -The final score and ranking of comprehensive evaluation

\begin{tabular}{|c|c|c|}
\hline feasible mode & the total score & ranking \\
\hline Mode I & 80.282 & 3 \\
\hline Mode II & 66.759 & 5 \\
\hline Mode III & 92.110 & 1 \\
\hline Mode IV & 72.869 & 4 \\
\hline Mode V & 83.294 & 2 \\
\hline
\end{tabular}


It can be seen from the above table that the model III has the highest score in the comprehensive evaluation of the feasible mode of the AGC auxiliary service, followed by the pattern five, the mode one, the mode four, the mode two,

\section{Conclusions}

Above all, we can infer that the mode III "matching trading, uniform clearing" in the decentralized is more suitable for Chinese present ancillary service period.

\section{Acknowledgements}

The paper was supported by the Science and Technology Project Fund of the State Grid Corporation of China.

\section{References}

1. P. Yao, Y. Yang, L. Wei, K. Zhang, Evaluation of AGC Service Based on Costeffective, J. Proceedings of the CSU-EPSA, 26 (2014) 77-80

2. Y. Huang, J. Shang, C. Kang, Q. Xia, Y. Meng, N. He, Operation Mechanism and Model of Electric Power Ancillary Service Market,J. Automation of Electric Power Systems, 27 (2003) 33-36.

3. J. Zou, Research on Market Pricing and Transaction Mode of Auxiliary Service, D. North China Electric Power University, (2012)

4. B. C. Ervural, S. Zaim, O. F. Demirel, Z. Aydin, D. Delen, An ANP and fuzzy TOPSIS-based SWOT analysis for Turkey's energy planning, Renewable and Sustainable Energy Reviews, ISSN. 12 (2017) 1364-0321, 